\title{
Atuação do psicólogo no centro de atenção psicossocial para criança e adolescente
}

\author{
Psychologist acting at the psychosocial care center for children and adolescents \\ Actuacion del psicólogo en el centro de atención psicosocial para niños y adolescentes
}

Recebido: 07/06/2021 | Revisado: 23/06/2021 | Aceito: 27/06/2021 | Publicado: 11/07/2021

\author{
Jeferson Rodrigues \\ ORCID: https://orcid.org/0000-0002-8612-9088 \\ Universidade do Sul de Santa Catarina, Brasil \\ E-mail: jeferson.rodrigues@ufsc.br \\ Fernando Kimura \\ ORCID: https://orcid.org/0000-0002-3269-3898 \\ Universidade do Sul de Santa Catarina, Brasil \\ E-mail: fe.kimura@gmail.com \\ Liliane Gonçalves Marques \\ ORCID: https://orcid.org/0000-0003-2201-9389 \\ Universidade do Sul de Santa Catarina, Brasil \\ E-mail: lilianegoncalvesmarques@gmail.com \\ Vanessa Vinícia Costa \\ ORCID: https://orcid.org/0000-0001-8018-8151 \\ Universidade do Sul de Santa Catarina, Brasil \\ E-mail: vanessavcosta@gmail.com \\ Fernanda Costa Nicolazzi \\ ORCID: https://orcid.org/0000-0002-1868-8531 \\ Universidade Federal de Santa Catarina, Brasil \\ E-mail: nicolazzifernanda@gmail.com \\ Gisely Pereira Botega \\ ORCID: https://orcid.org/0000-0001-7942-4938 \\ Universidade do Sul de Santa Catarina, Brasil \\ E-mail: gibotega@gmail.com \\ Sara Mendes Boeira Lopes \\ ORCID: https://orcid.org/0000-0002-0360-0234 \\ Universidade Federal de Santa Catarina, Brasil \\ E-mail: saramblopes@gmail.com
}

\begin{abstract}
Resumo
Trata-se de um artigo de relato de experiência que teve como o objetivo descrever a atuação do psicólogo em um Centro de Atenção Psicossocial para criança e adolescente no município de Florianópolis (SC). A experiência adveio de uma vivência por estudantes em uma atividade teórico-prática de uma disciplina do Curso de Graduação em Psicologia da Universidade do Sul de Santa Catarina no segundo semestre do ano de 2019. Foi realizado um projeto para conhecer o serviço e a atuação do psicólogo. O resultado refletiu a formação profissional e a ética do desejo para fortalecer a clínica e a política no cotidiano do trabalho. Conclui-se que a atuação do psicólogo neste serviço atravessa as competências específicas preconizadas pela legislação do exercício profissional, as diretrizes da Rede de Atenção Psicossocial, código de ética a partir do momento que a cada demanda e contexto se exige uma reinvenção da atuação do psicólogo.
\end{abstract}

Palavras-chave: Serviços de saúde mental; Serviços de saúde da criança; Psicologia da criança; Ensino superior.

\begin{abstract}
This is an experience report article that aimed to describe the acting of the psychologistin a Psychosocial Care Center for children and adolescents in the city of Florianópolis (SC). The experience came from an experience by students in a theoretical-practical activity of a discipline of the Undergraduate Course in Psychology at the University of the South of Santa Catarina in the second semester of 2019. A project was carried out to learn about the service and the acting of the psychologist. The result reflected the professional training and the ethics of the desire to strengthen the clinic and politics in daily work. It is concluded that the psychologist's acting in this service goes through the specific competences recommended by the legislation of professional practice, the guidelines of the Psychosocial Care Network, a code of ethics from the moment that each demand and context requires a reinvention of the psychologist's acting.
\end{abstract}

Keywords: Mental health services; Child health services; Psicología infantil; Education, higher. 


\section{Resumen}

Es un artículo de informe de experiencia con objetivo de describir el actuacion del psicólogo en un Centro de Atención Psicosocial para niños y adolescentes en Florianópolis (SC). La experiencia provino de una vivencia de estudiantes en actividad teórico-práctica de disciplina del Curso de Pregrado en Psicología en la Universidad del Sur de Santa Catarina en el segundo semestre de 2019. Se llevó a cabo un proyecto para aprender sobre el servicio y el actuacion del psicólogo. El resultado reflejó la formación profesional y la ética del deseo de fortalecer la clínica y la política en el trabajo diario. Se concluye que la actuación del psicólogo en este servicio pasa por las competencias específicas recomendadas por la legislación de práctica profesional, las pautas de la Red de Atención Psicosocial, un código de ética desde el momento en que cada demanda y contexto exige una reinvención del desempeño del psicólogo.

Palabras clave: Servicios de salud mental; Servicios de salud del niño; Psychology, child; Educación superior.

\section{Introdução}

O Centro de Atenção Psicossocial (CAPS) está inserido dentro da Atenção Psicossocial Estratégica da Rede de Atenção Psicossocial (Brasil, 2017), sendo constituído por equipe interdisciplinar e realiza prioritariamente atendimentos às pessoas com sofrimentos ou transtornos mentais graves e persistentes, incluindo aquelas com necessidades decorrentes do uso de álcool e outras drogas ou outras situações clínicas que impossibilitem estabelecer laços sociais e realizar projetos de vida (Tszesnioski, Nobrega, Lima \& Fagundes, 2015). O trabalho nos CAPS é realizado prioritariamente em espaços coletivos de forma articulada com os outros pontos de atenção da rede de saúde e das demais redes. O cuidado é desenvolvido mediante projeto terapêutico singular e envolve em sua construção a equipe, o usuário e sua família. O Centro de Atenção Psicossocial Infantil (CAPSi) é um serviço de atenção cotidiana direcionado ao atendimento de crianças e adolescentes com sofrimento psíquico grave. Estão incluídos nessa categoria crianças e adolescentes com autismo, psicoses, neuroses graves entre outros transtornos (Brasil, 2014). A organização do processo de trabalho envolve uma equipe e gestor que planejam, executam e avaliam os resultados das intervenções. O profissional psicólogo possui um amplo espectro de atuação no CAPSi e dentre as linhas está a construção de práticas que favoreçam processos de subjetivação para que o sujeito tenha oportunidade de se (re)posicionar frente a si e ao mundo.

Destarte, durante a formação no Curso de Graduação em Psicologia da Universidade do Sul de Santa Catarina, foi vivenciada uma unidade de aprendizagem relativa à criança e adolescente e que constava como atividade avaliativa a visita técnica a um serviço de saúde ou educação para conhecer a atuação do psicólogo. Na qualidade de estudantes de psicologia, escolheu-se o CAPSi como lugar de vivência para elaborar o estudo acadêmico.

Neste sentido, tem-se como questão norteadora: como se dá atuação do/a psicólogo/a no Centro de Atenção Psicossocial criança e adolescente de Florianópolis? A partir deste contexto, tivemos como objetivo relatar a atuação do psicólogo no Centro de Atenção Psicossocial Criança e Adolescente de Florianópolis.

A importância deste estudo está na temática, pois foi ausente produção específica sobre a atuação do psicólogo no CAPSi em base de dados, no desenvolvimento de estudos acadêmicos durante a formação da graduação para ampliar o escopo das competências exigidas pelas Diretrizes Curriculares Nacionais e Projeto Pedagógico do Curso, refletir a formação e atuação do psicólogo no CAPSi e contribuir com a comunidade acadêmica com o tema estudado.

Parte-se da perspectiva de que quanto mais o profissional psicólogo estiver consciente de sua condição humana, social e política, de sua função de trabalhador na tríade Estado, Mercado e Sociedade, em que pese o sistema político, mais apto estará para eleger instrumentos de trabalho que visem o resgate dessa mesma condição de sujeito-cidadão para as crianças e adolescentes com sofrimento psíquico e transtornos mentais. Isso implica uma posição profissional sobre o contexto das políticas públicas intersetoriais, em especial, as de saúde, assistência social, saúde mental e educação no Brasil. (Mendonça, Souza \& Guzzo, 2015)

Assim posto, salienta-se que é a formação política para além da formação técnica na graduação em psicologia o que 
possibilita aproximação com a constituição de uma reflexão-ação critico-propositiva de que a cidadania é um front para a atuação profissional. O psicólogo, seja estudante e/ou profissional, tem a possibilidade de contribuir com a participação política e social de crianças e adolescentes, para tanto se faz necessário para este ter a clareza de sua condição profissionalcidadão e que esta condição provém pela experiência e formação, desde uma ética do desejo. Com a delimitação da condição do lugar do psicólogo como cientista-clínico, educador e político, este socialmente advertido de sua função para além de seu juramento profissional e seu código de ética, possui também a função de mobilizador político (Souza, Paiva, Oliveira, Mello \& Alencar, 2014).

\section{Metodologia}

Trata-se de um estudo descritivo, do tipo relato de experiência, a partir da vivência de estudantes da quarta fase do Curso de Graduação em Psicologia da Universidade do Sul de Santa Catarina em um Centro de Atenção Psicossocial para crianças e adolescentes e correlacionado com a revisão narrativa de literatura. Conforme Minayo (2014) estudo descritivo permite contextualizar e descrever a realidade do objeto do estudo para ampliar seu entendimento, pois as vivências descritas aprofundam o conhecimento e os saberes da realidade estudada. Segundo Santos (2008), relato de experiencia consiste em uma sistematização a partir da correlação entre a sustentação teórica e a vivência da experiência realizada, integra a linguagem formal e informal e de maneira mais sintética. A revisão narrativa de literatura para Prado, Morillas-Bulnes e Moran-Pena (2014) descreve o contexto das produções de um determinado assunto e permite analisar os estudos a partir da interpretação e análise crítica pelo pesquisador, sem um método predeterminado e a seleção dos estudos são planejados e organizados pelo investigador a partir de um interesse e acesso às produções. Este relato emergiu de uma atividade avaliativa de uma unidade de aprendizagem (disciplina) do Curso citado relativa à criança e adolescente. Para tanto, foi escolhido o CAPSi como local para estudar a atuação do psicólogo neste serviço. 
Figura 1 - Fluxograma dos procedimentos realizados.

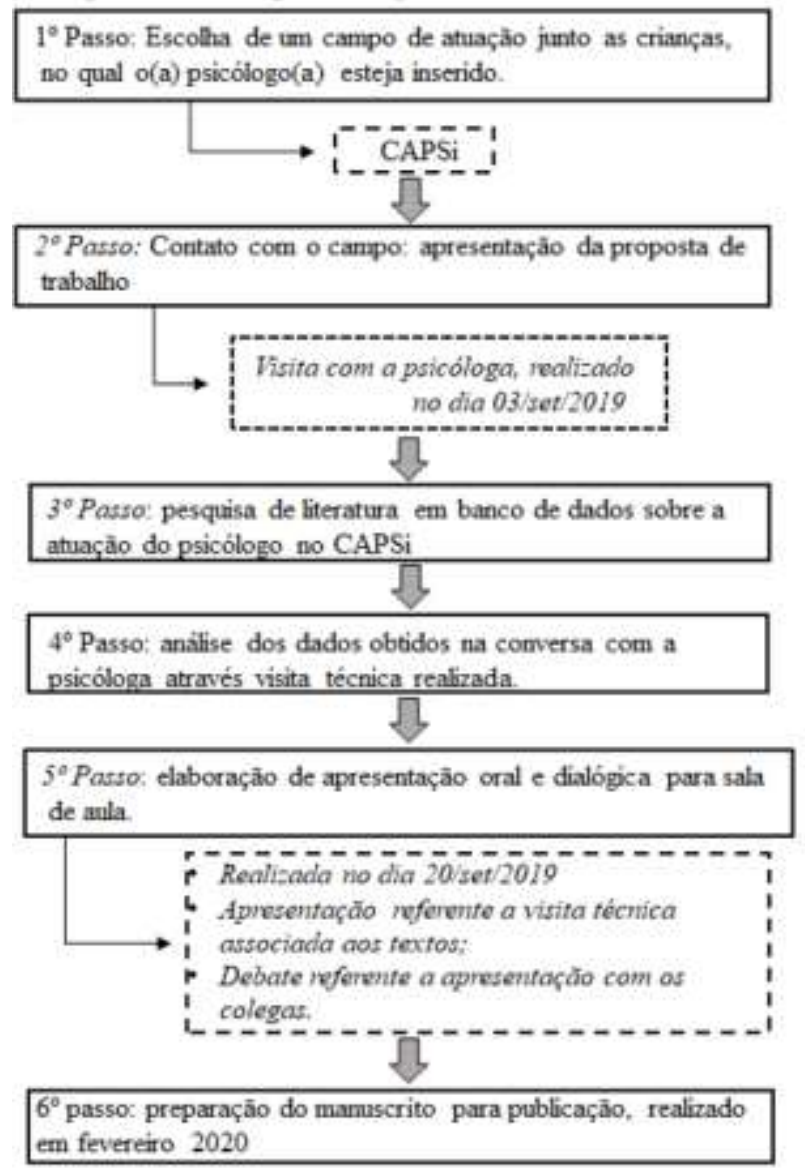

Fonte: Autores (2020).

Conforme fluxograma esboçado na figura acima, tomou-se como passos: 1) Elaboração de um projeto que preparasse a ida a campo e norteasse a apresentação oral em sala de aula e da construção de um relatório final. 2) Agendamento e visita com a psicóloga, onde foi levado uma carta de apresentação do trabalho e que a instituição autorizou a realização da atividade. 3) Pesquisa de literatura em banco de dados sobre a atuação do psicólogo no CAPSi. 4) Análise dos dados obtidos na conversa com a psicóloga e visita técnica realizada. 5) Elaboração de apresentação oral e dialógica para sala de aula. 6) Preparação do manuscrito para publicação.

Realizou-se uma revisão narrativa de literatura, (Prado et al, 2014), onde buscou-se por produções científicas no banco de dados no Portal CAPES (Brasil, 2021) com o objetivo de acessar produções científicas com o foco na atuação do psicólogo no CAPSi. Foi utilizado a combinação 1 Centro de Atenção Psicossocial infantil em um total de 248 produções e a combinação 2 psicologia, centro de atenção psicossocial infantil com 77 produções. Foi ausente uma produção específica sobre o objeto deste relato. 
Quadro 1 - Produções Científicas que se aproximaram do objeto de estudo atuação do psicólogo no CAPSi.

\begin{tabular}{|c|c|}
\hline $\begin{array}{c}\text { Identificacāo } \\
\text { do estudo }\end{array}$ & Referència campleta \\
\hline El & 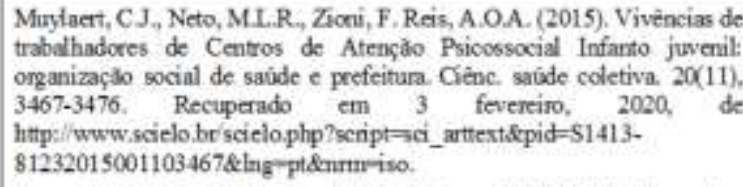 \\
\hline E2 & 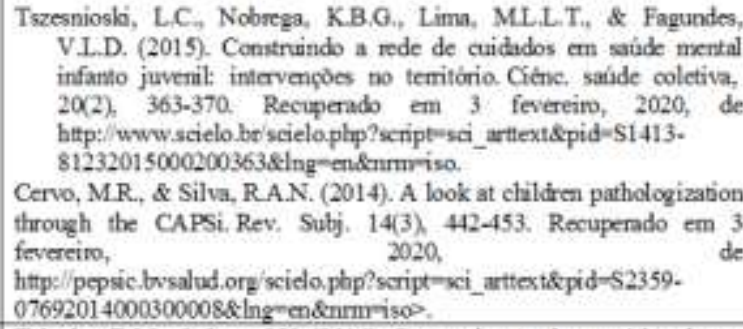 \\
\hline E4 & 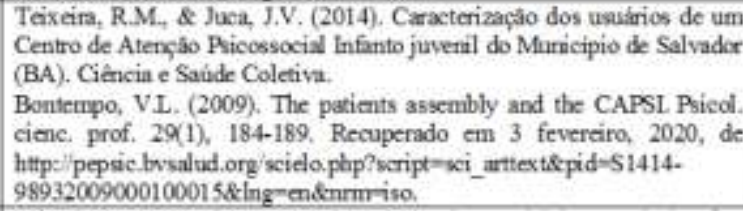 \\
\hline E6 & 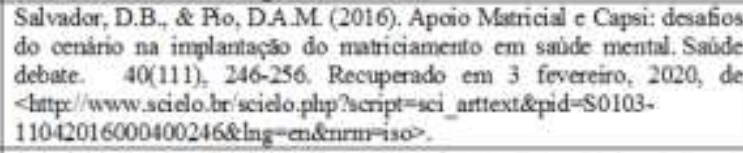 \\
\hline E7 & 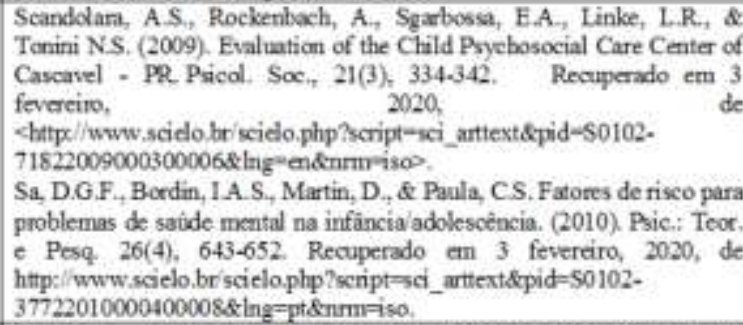 \\
\hline E9 & $\begin{array}{l}\text { Cantele, J., Arpini, D.M., \& Roso, A.R. (2012). A psicologia no atual } \\
\text { modelo de atençio cm saude mental. Picologia: Ciéncia e Profissio. } 32 \text {, } \\
910 / 4-925 \text {. }\end{array}$ \\
\hline E10 & 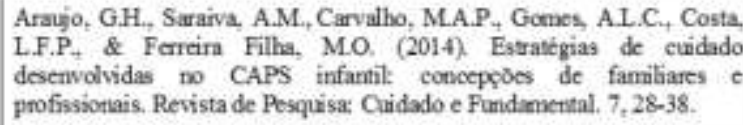 \\
\hline
\end{tabular}

Fonte: Autores (2020).

Conforme quadro acima, após leitura dos títulos e resumos das produções, foram lidos textos completos dos principais estudos que se aproximaram do objeto deste relato e que se articulavam com o objetivo e dados da conversa com a psicóloga foram escolhidos conforme abaixo. Salienta-se que por não se tratar de um estudo de natureza revisão de literatura, reconhecese a limitação da busca em especial em bases internacionais.

O relato metodológico foi elaborado por etapas conforme o quadro 1. Por se tratar de um relato a partir de uma atividade avaliativa da disciplina citada, o plano de ensino e as orientações da professora foram guias para formular o projeto. Assim, os alunos se reuniram em grupo presencialmente e construíram um projeto a partir do objeto de estudo atuação do psicólogo em CAPSi. O projeto foi organizado conforme os tópicos introdução, questão norteadora, objetivos, método, cronograma e reflexões finais. Ato contínuo, realizou-se reunião com a professora para orientação do estudo. A partir do projeto, um dos alunos fez contato com a coordenadora e psicóloga do serviço de saúde mental onde foi apresentado a proposta via telefone e o agendamento da ida pelos alunos ao campo. No dia agendado foram tomados os cuidados éticos, levado carta de apresentação da instituição e seguiu-se um roteiro para o diálogo com a psicóloga e visita técnica ao serviço. O roteiro constava, em um primeiro momento, de como se dava o acesso, acolhimento, acompanhamento, avaliação de casos e do 
serviço, e a alta dos pacientes no serviço. Em um segundo momento, como o serviço se articulava com a política de saúde mental do município, o processo de trabalho e a atuação específica do psicólogo. No encontro foi observado o sistema de informação e formas de registro do trabalho. A partir da visita técnica, foi construído um relatório e na medida que emergiam dúvidas a psicóloga do serviço era consultada. Para o aprofundamento do relato de experiência foi realizada uma revisão de literatura do tipo narrativa para fundamentar as reflexões do estudo. Foi ausente uma literatura específica sobre a atuação do psicólogo em CAPSi o que aponta a relevância deste estudo e a escolha dos artigos baseou-se na aproximação com o objeto empírico. Com a visita técnica, a participação efetiva da psicóloga e os estudos científicos foi possível finalizar o relatório final da atividade. Foi realizado orientação com a professora onde o relato finalizou com a apresentação oral e dialógica em sala de aula. A apresentação oral teve o tempo de sessenta minutos e o debate circulou sobre a formação do psicólogo para o CAPSi. Após o atendimento dos fins acadêmicos da disciplina, o manuscrito foi preparado para relatar a experiência

\section{Resultados e Discussão}

O município de Florianópolis conta com uma população aproximada de 500 mil habitantes segundo o Instituto Brasileiro de Geografia e Estatística (Instituto Brasileiro de Geografia e Estatística, 2020). Em que pese este número populacional, este município possui dois CAPS Ad, um CAPS II e um CAPSi. O município segue o preconizado pela política do Ministério da Saúde no que se refere a implantação de redes de serviços locais, descentralizados e extra-hospitalares de atenção à saúde mental. No que se refere ao contexto do Centro de Atenção Psicossocial para Infância e Adolescência, este foi criado em 2004 após um ajuste de conduta do Ministério Público. Naquela época as crianças eram atendidas pela equipe do CAPS II junto com os adultos. Isto se deu após a constatação de, tanto na rede pública de educação quanto na de saúde do município, problemas graves de sofrimento mental em crianças e adolescentes sem que houvesse um serviço especializado que pudesse ser referenciado para esses casos. (Brasil, 2004)

Em face disso, o Ministério da Saúde, através de uma Portaria incluiu o município como um dos prioritários quanto à implantação de Centro de Atenção Psicossocial para crianças e adolescentes (CAPSi) durante o ano de 2004.

O CAPSi foi criado com o objetivo de atender crianças e adolescentes que apresentassem sofrimento psíquicos severos e persistentes em diferentes níveis de intensidade que fossem moradores da cidade de Florianópolis e tivessem entre 0 (zero) a 18(dezoito anos) e na lógica da reforma psiquiátrica. Atualmente esta característica se mantém. O serviço está composto por 3 Psicólogas (1 coordenadora - 30hs cada), 2 Enfermeiras (40 hs), 2 Psiquiatras (30 e 20 hs), 1 Assistente Social (30 hs), 1 Neuropediatra (5 hs), 3 técnicos de enfermagem ( 40 e 30 hs), 2 assistentes administrativos ( 30 e 20 hs), 1 estagiária de psicologia (12 hs), 1 Auxiliar de Serviço Geral e 1 Vigia (40 hs). Destaca-se que as segundas feiras no turno vespertino o serviço realiza reunião técnica para discutir casos e demais pautas.

Os usuários chegam ao CAPSi encaminhados das mais diversas instituições, tais como: Estratégia da Saúde da Família (ESF), Núcleos Ampliado da Estratégia da Saúde da Família (NASF), Promotoria e Juizado da Infância e Juventude, Escolas estaduais e municipais, Conselhos Tutelares, Serviços da Assistência Social e hospitais. A equipe do CAPSi atende, avalia os casos e encaminham de forma co-responsável para outro dispositivo caso não seja elegível para o serviço. Salienta-se que há uma fragilidade de atenção à infância e adolescência no âmbito da atenção primária de saúde (Unidades de Saúde e NASF), ou seja, o agravo de saúde mental na infância e adolescência é concebido como especialidade. Desta forma, várias situações que chegam ao CAPSi poderiam ter sido acolhidas e cuidadas na atenção primária e consequentemente muitos agravos em saúde mental poderiam ser evitados.

Quando a criança e o adolescente chegam ao CAPSi eles passam pelo acolhimento e avaliação para entender se é um caso CAPSi, sendo, é elaborado o Projeto Terapêutico Singular (PTS). Este projeto é construído em conjunto com o usuário e família e constituído pelas atividades que eles e suas famílias farão no CAPSi e em outros pontos da rede. O PTS é gerenciado 
pelo Técnico de Referência (TR), ou seja, o profissional de referência acompanha e monitora a avaliação, discussão e modificação do PTS. Salienta-se que os PTSs são dinâmicos e se modificam no decorrer da trajetória do usuário no serviço. No PTS da criança e do adolescente é incluída a articulação da equipe com a rede de atenção psicossocial (RAPS) e outras instituições como assistência social, justiça, educação, cultura, através de visitas e reuniões com as mesmas. Os PTS são revisitados mensalmente pelos técnicos de referência e discutidos em equipe quando necessário. (Brasil, 2004)

A equipe do CAPSi concebe a criança e os adolescentes como sujeitos psíquicos e de direitos, ou seja, sujeitos sabedores de suas demandas, sujeitos integrais que estão em transformação em seu contexto familiar e social. Logo, são diversos os motivos que levam a procura pelo CAPSi, seja de algum estranhamento com o próprio processo de mudança sentida por si ou por um outro, até situações como casos de auto-agressividade, heteroagressividade, situações de tristeza, angústia e raiva que suplantam a vida da criança e adolescente, vontade intermitente de morrer e isolamento social. (Brasil, 2014)

Para dar conta desta demanda é pactuado ações com a rede intersetorial, pois entende-se que as demandas clínicas são também políticas e intersetoriais. Dentre os dispositivos que fazem parte da rede estão: Juizado e Promotorias da Infância e Juventude, Conselhos Tutelares, Universidades, Escolas e programas de Educação especial, Hospitais Gerais, Unidades de Saúde, NASF, UPAS, Assistência Social (Serviços Assistência nos três níveis de Complexidade), Projetos Sociais/ONGS.

A partir da formação em psicologia e apto ao exercício profissional, o trabalho do psicólogo no CAPSi dependerá do processo de seleção, seja por concurso público ou de outro tipo. A psicóloga que nos recebeu no serviço é concursada e atua mais de dez anos na unidade. A questão é que fica ausente a exigência de uma formação específica para o psicólogo lidar com criança e adolescente, em que pese o município estudado, e a formação de psicólogo é entendida como suficiente para dar conta deste trabalho, ou seja, um recém graduado ou profissional com vasta experiência em outra área pode ocupar a vaga. Por um lado, a formação do psicólogo é generalista, o CAPSi especializado em criança e adolescente. Por outro, há distintas formações em Psicologia no Brasil e este recém graduado pode ter tido ou não experiência teórico e clínica com crianças e adolescentes. Ainda assim, os CAPS's são norteados pelo processo de Reforma Psiquiátrica na qual a desinstitucionalização e reflexão crítica sobre o processo de trabalho e o contexto estrutural devem ser pressupostos para os profissionais que queiram se engajar neste tipo de serviço, o que processo seletivo algum garante. Faz-se aqui um briefing, é imprescindível que os Cursos de Graduação em Psicologia preconizem este ensino e experiência clínica, pois o foco é a mirada em um amplo projeto profissional que fortaleça as competências e habilidades do psicólogo para as mais diversas áreas de atuação. Isso remete o compromisso da formação em Psicologia com as políticas públicas voltadas a crianças e adolescente (Cantele, Dorian \& Roso, 2012).

Assim, a formação na graduação pode permitir ou não a realização da clínica com crianças e adolescentes, mas será o desejo pessoal que direcionará a práxis profissional. É o desejo que afeta, mobiliza e produz implicação com o campo da clínica e da política. A ética do desejo indica o lugar que o profissional quer ocupar sobre o serviço, a clínica, a especialização, supervisão, terapia pessoal, vinculo com instituição de formação.

A atuação do psicólogo envolve atendimento individual e coletivo, atenção à crise, coordenação de oficinas terapêuticas, atendimentos familiares, acolhimento inicial, avaliação de caso, articulação intersetorial, relatórios, visita domiciliares, discussão de caso intra e intersetorial. Como atribuição específica tem a psicoterapia e produção de laudos, principalmente para escolas e judiciário. Para dar conta destas atribuições, cada psicólogo do serviço fez uma formação pós lotação no serviço seja em Gestalt Terapia, Orientação Analítica, Sistêmica, Cognitivo Comportamental.

Cada psicólogo faz sua psicoterapia pessoal, participa da supervisão clínico-institucional que acontece no serviço, realizam supervisão dos casos que estes atendem. O trabalho do psicólogo tem um efeito: família que se organiza para cuidar, paciente que volta à escola, retoma as relações sociais, se reinsere na vida social, faz representação subjetiva pela arte. Para a 
psicóloga que recebeu os estudantes "a ética do desejo indica o lugar que o profissional quer ocupar sobre o serviço, a clínica, a especialização, supervisão, terapia pessoal, vínculo com instituição de formação".

Assim posto, salienta-se que é a formação política para além da formação técnica na graduação em psicologia o que possibilita aproximação com a constituição de uma reflexão-ação critico-propositiva de que a cidadania é um front para a atuação profissional. De antemão, afirmo que para o psicólogo, seja estudante e/ou profissional, contribuir com a participação política e social de crianças e adolescentes se faz necessário para este ter a clareza de sua condição profissional-cidadão e que esta condição provém pela experiência e formação, desde uma ética do desejo. Com a delimitação da condição do lugar do psicólogo como cientista-clínico, educador e político, este socialmente advertido de sua função para além de seu juramento profissional e seu código de ética, possui também a função de mobilizador político.

Nesse contexto, pode-se pensar caminhos a serem desbravados a partir do ethos da polis no Centro de Atenção Psicossocial para crianças e adolescentes pelo profissional e equipe interdisciplinar. No horizonte está a aproximação-transição de usuários para cidadãos leitores de realidade, participativos e agentes transformadores. Isso significa pensar, propor e avaliar estratégias para promover o protagonismo infanto-juvenil na elaboração e controle social das políticas públicas. Dessa forma, destaca-se que qualquer que seja a proposta de um Projeto para mobilização e organização política neste contexto, esta deve ser elaborada em conjunto profissional, gestor, crianças, adolescentes e famílias, para que o sentimento de pertença e identidade de grupo esteja presente em todo o processo e alinhamentos possíveis.

Isto porque, para Trevisan (2012), "a cidadania infantil relaciona-se intimamente com as posições que as crianças ocupam e o reconhecimento que obtêm na sociedade mais vasta, particularmente em esferas públicas de atuação". Logo, "a pertença e a capacidade de tomar parte em processos de tomada de decisão, e de ter uma opinião em assuntos que importam exige uma visão mais vasta dos sentidos da sua participação".

A atuação do psicólogo no CAPSi fez refletir quais conhecimentos, competências e habilidades o aluno em formação deve ter contato na graduação para se sentir apto a compor a equipe do serviço estudado. Isto porque, embora não seja função da graduação preparar para tudo, tendo em vista a diversidade no ensino da psicologia no Brasil, mas ofertar o máximo de experiência possível e o CAPSi é uma delas, pois é um serviço importante no contexto do Sistema Único de Saúde e na Política de Saúde Mental.

Na perspectiva do Setor da Educação, no cenário da graduação, os mecanismos de avaliação internos à instituição de ensino e, externo preconizados pelo Ministério da Educação através do Instituto Nacional de Estudos e Pesquisas Educacionais Anísio Teixeira (2017), pelo Sistema Nacional de Avaliação da Educação Superior - SINAES, pelo instrumento de avaliação de Cursos de Graduação Presencial e a Distância também não disponibilizam de item que garanta conteúdos e práticas com crianças em serviços como o CAPSi. Logo, fica a critério da instituição, através de sua matriz curricular e Projeto Pedagógico de Curso, ofertar esta experiência.

Na perspectiva do Setor Saúde, por um lado, as atribuições profissionais preconizadas na Portaria GM n $^{\circ} 336$ (Brasil, 2002) são gerais e para a equipe, sem menção por categoria profissional, e relacionadas a prestação de atendimento individual, incluindo medicamentoso, psicoterápico, de orientação, e diversos, assim como o atendimento em grupos por meio da psicoterapia e outras modalidades, em oficinas terapêuticas, visitas e atendimentos domiciliares, atendimentos à família, atividades em âmbito comunitário com o objetivo integrar socialmente o indivíduo e desenvolvimento de ações inter-setoriais, com destaque para a assistência social, educação e justiça.

Todavia, os fazeres mencionados pela psicóloga neste relato contemplam a Portaria GM no 336 (Brasil, 2002) e o contexto do trabalho da realidade local, grosso modo, e a especificidade da atuação do psicólogo no CAPSi segue, de certo modo, a lei do exercício profissional, (Lei n. 4.119, 1962), como o diagnóstico psicológico, orientação e seleção profissional, psicopedagógica e solução de problemas de ajustamento. O que torna a atuação específica do psicólogo no CAPSi, para além 
das atividades privativas e que serve para outros serviços são as demandas intersetoriais que se relacionam com a criança e o adolescente, pois embora exista uma clínica com uma especificidade, situações de criança e adolescentes, são as demandas, sejam clínicas, políticas, jurídicas, escolares (Costa \& Ferreira Filha, 2015).

A atuação do psicólogo no CAPSi vai ser atravessada, direcionada pela Ética do desejo, é esta ética quem o conduzirá a realizar uma práxis engajada clínica e politicamente alicerçada com o processo de Reforma Psiquiátrica e no modelo de Atenção Psicossocial. É esta mesma ética do desejo que fortalecerá e ampliará a atuação do psicólogo no que se refere a organização política, ao manejo de um processo civilizatório, democrático e participativo nos serviços de saúde mental (Guerra, 2005).

Ética do desejo implica uma interrogação sobre o próprio desejo, uma interrogação sobre o lugar que quer ocupar, porque isto? Porque não outra? Mesmo sabendo que não há completude. Ética do desejo se trata do desejo e da ação, ou seja, na relação com o outro depende o lugar do próprio desejo. Ética como aposta de criação, de reconstrução pela vivência. Ser ético é não trair o próprio desejo (Figueiredo \& Silva Filho 1996).

O cuidado prestado pelo psicólogo baseado na Reforma Psiquiátrica é um cuidado em Liberdade como diretriz Clínica. A liberdade como direito da criança e do adolescente, na prática, se traduz pela minimização de espaços segregadores, no consentimento para o tratamento, que a criança possa na medida do possível participar das decisões, fortalecendo os laços sociais (Conselho Federal de Psicologia, 2013). Cuidar é construir condições de liberdade e capacidade de se incluir na cidade, de fazer caber a diferença pela singularidade, no universal da cidadania com cada pessoa (Araujo, Saraiva, Carvalho, Gomes, Costa \& Ferreira Filha, 2014).

No entanto, a atuação do psicólogo fundamentada no cuidado em liberdade requer do profissional a capacidade de saber fazer leituras e análises políticas para propor projetos desinstitucionalizantes, para promover a formação política, a mobilização para cidadania desde sua formação engajada em centros acadêmicos, diretórios centrais estudantis e levar as discussões ao local de trabalho pelas assembléias nos serviços (Bontempo, 2009), contribuição na criação de associações de usuários e familiares, cursos de formação política vinculadas a espaços fora do CAPSi e contribuição com as entidades profissionais e controle social.

\section{Considerações Finais}

A partir do relato da atuação do psicólogo no Centro de Atenção Psicossocial para Criança e Adolescente de Florianópolis, reflete-se a responsabilidade e o compromisso que cada instituição de ensino possui com a formação do psicólogo também para o Sistema Único de Saúde e as demandas de criança e adolescente, seja clínica, política e pedagógica, atravessada pela ética do desejo.

Refletiu-se que o psicólogo ao acessar e vincular-se a um CAPSi, ele está imerso a um projeto civilizatório, democrático e de direitos, isto significa que a cada momento este profissional se reinventa, tendo em vista a diversidade de demandas intersetoriais que atravessam o contexto da criança e adolescente no campo da saúde mental.

A atuação é polissêmica, pois cada profissional e equipe atribuem vários sentidos a esta, específica pois envolve um limiar entre atividade privativa e demandas intersetoriais relativas para além da faixa etária e complexa, tendo em vista que a formação para a atuação é intermitente, inacabada e que requer investimento financeiro, afetivo e constantes avaliações sobre a prática.

O CAPSi se mostrou um lugar de cuidado, que faz conexões, que questiona a vida, que é estratégico para intervir no território, que tem a contribuir com uma cidadania inventiva.

Sugere-se para trabalhos futuros a investigação sobre a necessidade de formação específica do psicólogo para atuar em CAPSi e como esta deveria ser, pois se trata de uma formação acadêmica generalista e um trabalho no serviço 
especializado. Também se recomenda investigação sobre o perfil da força de trabalho dos psicólogos em CAPSi para se conhecer a realidade das condições de trabalho e planejar e qualificar essa atuação com a parceria entre universidades e o poder executivo.

\section{Referências}

Araujo, G. H., Saraiva, A. M., Carvalho, M. A. P., Gomes, A. L. C., Costa, L. F. P., \& Ferreira Filha, M. O (2015). Estratégias de cuidado desenvolvidas no CAPS infantil: concepções de familiares e profissionais. Revista de Pesquisa Cuidado é Fundamental Online, 7,28-38. https://www.redalyc.org/articulo.oa?id=505750949003

Bontempo, V. L. (2009). A assembléia de usuários e o CAPSI. Psicologia: ciência e profissão. Psicol. Cienc. Prof, 29(1), 184-189. https://doi.org/10.1590/S1414-98932009000100015

Brasil (1962). Presidência da República. Lei n. 4.119, de 27 de agosto de 1962. Dispõe sobre os cursos de formação em psicologia e regulamenta a profissão de psicólogo. Diário Oficial da União, Brasília. Seção 1, p. 9253.

Brasil, (2021). Ministério da Educação. Portal Capes. https://www.capes.gov.br/.

Brasil (2002). Ministério da Saúde. Gabinete do Ministro. Portaria n. 336, 19 de fevereiro de 2002. Estabelece CAPS I, II e III, CAPS i II e CAPS ad II. Diário Oficial de União, Brasília. Edição n. 34, Seção 1, p. 22.

Brasil (2017). Ministério da Saúde. Gabinete do Ministro. Portaria n. 3.588, de 21 de dezembro de 2017/ Altera as Portarias de Consolidação n. 3 e n. 6, de 28 de setembro de 2017, para dispor sobre a Rede de Atenção Psicossocial, e dá outras providências. Diário Oficial da União. Brasília. Edição n. 245, Seção 1, p. 236-238.

Brasil, (2004). Ministério da Saúde. HumanizaSUS: prontuário transdisciplinar e projeto terapêutico. Autor.

Brasil, (2004). Ministério da Saúde. Saúde mental no SUS: os centros de atenção psicossocial. Autor.

Brasil, (2014). Ministério da Saúde. Atenção psicossocial a crianças e adolescentes no SUS: tecendo redes para garantir direitos. Autor.

Cantele, J. A., Dorian, M. \& Roso, A. A. (2021) Psicologia no modelo atual de atenção em saúde mental. Psicologia: Ciência e Profissão, 32(4), 910-925. https://doi.org/10.1590/S1414-98932012000400011

Conselho Federal de Psicologia - CFP. (2013). Referências técnicas para atuação de Psicólogos(as) no CAPS - Centro de Atenção Psicossocial. Autor.

Costa, L. P., \& Ferreira Filha, M. O. (2015). Estratégias de cuidado desenvolvidas no CAPS infantil: concepções de familiares e profissionais. Revista de Pesquisa Cuidado é Fundamental Online, 7(1), 28-38.

Figueiredo A. C., \& Silva Filho J. F. (1996). Ética e Saúde Mental. Topbooks.

Guerra, A. M. C. (2005). A psicanálise no campo da saúde mental infanto-juvenil. Psychê, 9(15), 139-154.

Instituto Brasileiro de Geografia e Estatística - IBGE (2020). Dado populacional do município de Florianópolis de 2019. https://cidades.ibge.gov.br/brasil/sc/florianopolis/panorama.

Instituto Nacional de Estudos e Pesquisas Educacionais Anísio Teixeira; Sistema Nacional de Avaliação da Educação Superior. (2017) Instrumento de Avaliação de Cursos de Graduação Presencial e a Distância. Autor.

Mendonça, G. S., Souza, V. L. T.de, \& Guzzo, R. S. L. (2016). O conceito de ideologia na psicologia social de Martín-Baró. Revista Psicologia Política, 16(35), 17-33.

Minayo, M. C. S., (2014). O desafio do conhecimento: pesquisa qualitativa em saúde. (14a ed.), Hucitec.

Prado, M.L; Morillas-Bulnes, \& A; Moran-Pena, L.(2013). Investigación cualitativa en enfermería. Metodología y didáctica. (Cap. 16, pp 193-203). Paltex.

Santos, A.R. (2008). Metodologia científica: a construção do conhecimento. Lamparina.

Souza, C. de,. Paiva, I. L. de,. Oliveira, F. de., Mello, L. C. de A., \& Alencar, V. S,. (2014). Formação política como uma forma de enfrentamento à violência na juventude. Revista Psicologia Política, 14(30), 367-383.

Trevisan, G.P. (2012). Perspectivas sociológicas e educacionais em estudos da criança: as marcas das dialogicidades luso-brasileiras. (Cap. 2, pp 84-105). Minho: Centro de Investigação em Estudos da Criança da Universidade do Minho.

Tszesnioski, L. C., Nobrega, K. B. G., Lima, M. L. L. T., \& Fagundes, V. L. D.(2015). Construindo a rede de cuidados em saúde mental infanta juvenil: intervenções no território. Ciênc. saúde coletiva, 20(2), 363-370. 